\title{
Day Times Nanogram Per Milliliter Per Kilogram
}

National Cancer Institute

\section{Source}

National Cancer Institute. Day Times Nanogram Per Milliliter Per Kilogram. NCI

Thesaurus. Code C112259.

Days times nanograms per milliliter, divided by kilograms. 